\title{
Sodium nitroprusside-induced osteoblast apoptosis is mediated by long chain ceramide and is decreased by raloxifene
}

\author{
Sabine Olivier, Marianne Fillet, Michel Malaise, Jacques Piette, Vincent Bours, \\ Marie-Paule Merville, Nathalie Franchimont* \\ Department of Rheumatology, Laboratory of Clinical Chemistry and Human Genetics, CBIG, \\ CHU Sart-Tilman, University of Liège, 4000 Liege, Belgium
}

Received 9 September 2004; accepted 15 November 2004

\begin{abstract}
Release of high levels of nitric oxide (NO) is associated with osteoblastic cell death. The mechanisms of NO-induced cytotoxicity are not well documented and it is presently not known if estrogenic compounds prevent this effect. We studied the role of ceramides in cell death induced by the NO donor sodium nitroprusside (SNP) and we tested the possibility that 17 $\beta$-estradiol, the anti-estrogen ICI 182.780 and two selective estrogen receptor modulators raloxifene and tamoxifen modify osteoblastic cell apoptosis. SNP dose-dependently decreased MC3T3-E1 osteoblast viability, increased NO production in the culture media and enhanced the release of intracellular ceramides C22 and C24. Cell death induced by SNP was partially inhibited when MC3T3-E1 cells were pretreated with raloxifene and tamoxifen but was not modified when the cells were pretreated with $17 \beta$-estradiol or ICI 182.780. Cell death induced by SNP resulted from apoptosis as demonstrated by Annexin-V and propidium iodide labeling and a reduction of SNP-induced MC3T3-E1 apoptosis was confirmed in the presence of raloxifene and tamoxifen. SNP induction of C22 and C24 production was inhibited by a pretreatment with raloxifene but not with $17 \beta$-estradiol. Moreover, the synthetic ceramide C24 (0.75 and $1 \mu \mathrm{M})$ decreased MC3T3-E1 cell viability and osteoblast cell death induced by $\mathrm{C} 24$ was partially decreased by raloxifene and to a lesser extent by $17 \beta$-estradiol. These data demonstrate that SNP-induced cell death is mediated by the long chain ceramides C22 and C24 and that raloxifene protected osteoblast from apoptosis induced by SNP, an effect that might be relevant to its pharmacological properties on bone remodeling.
\end{abstract}

(C) 2004 Elsevier Inc. All rights reserved.

Keywords: Nitric oxide; Ceramides; Apoptosis; Raloxifene; Estrogen; Osteoblast

Nitric oxide (NO) is a free radical species that mediates numerous cellular effects including endothelium relaxation, neurotransmission or immune function [1]. NO is produced by bone cells and influences both osteoclastic and osteoblastic functions with a biphasic effect. Low levels of slowly released NO result in stimulation of osteoblast replication and function. On the contrary, higher amounts of rapidly released $\mathrm{NO}$ are associated with an inhibition of osteoblast proliferation and an induction of apoptosis [2,3]. Sex hormones, pro-inflammatory cytokines and mechanical constrain have been found to regulate NO production by bone cells [3-7]. Therefore, NO might be involved as a mediator of bone disease in postmenopausal osteoporosis or in inflammatory diseases.

\footnotetext{
* Corresponding author. Tel.: +324366 24 87; fax: +324366 7016 .

E-mail address: nfranchimont@ulg.ac.be (N. Franchimont).
}

Indeed, as demonstrated in vivo in mice with a targeted inactivation of the inducible NO synthase (iNOS) gene, activation of the iNOS pathway contributes to inflammation-induced osteoporosis though a decrease in bone formation caused by osteoblast apoptosis [8].

The proapoptotic effects of NO are mostly independent of cGMP but may involve the mitochondrial apoptotic pathway and activation of the caspases as well as the generation of ceramides depending on cell type [2]. Membrane-bound ceramides interact with proteins and are intracellular second messengers of apoptosis or stress signaling. The most common ceramides have acyl chain lengths of 16-24 carbon atoms (C16-C24). "Short ceramides" (C2 or C8 for example) are able to mimic the effect of proapoptotic agents such as tumor necrosis factor$\alpha$ [9]. Currently however, there are little informations concerning the specific types of ceramides generated in 
NO-induced cell-death and their effect on osteoblast viability. The aim of our study was first to investigate the effects on osteoblastic cell viability of high doses of NO pharmacologically (i.e. non-enzymatically) generated by sodium nitroprusside and to determine and characterize the role of ceramides in this process. Secondly, we looked at the role of estrogens in osteoblast apoptosis as these hormones inhibit bone resorption and bone turnover but also decrease osteoblast apoptosis induced by etoposide [10]. We compared the effects of $17 \beta$-estradiol, the antiestrogen ICI 182.780 and two selective estrogen receptor modulators (SERMs): raloxifene and tamoxifen which have estrogen agonistic properties on bone and antagonistic effects on breast [11]. Importantly, estrogens and raloxifene prevent the incidence of osteoporotic fractures in post-menopausal women [12-15]. We consequently examined whether $17 \beta$-estradiol and/or raloxifene modifies MC3T3-E1 osteoblastic cell viability in the presence of SNP. We also compared their effects on intracellular ceramide levels in response to SNP and on MC3T3-E1 osteoblastic cell death in the presence of the exogenous ceramide $\mathrm{C} 24$.

\section{Materials and methods}

\subsection{Reagents}

Raloxifene and ICI 182.780 were obtained from Eli Lilly (Indianapolis, IN, USA), tamoxifen and $17 \beta$-estradiol were purchased from Sigma-Aldrich (Schnelldorf, Germany). Raloxifene, tamoxifen, $17 \beta$-estradiol and ICI 182.780 were dissolved in ethanol at a concentration of $1 \mathrm{mM}$. Sodium nitroprusside (SNP) was obtained from ICN biomedicals (Asse, Belgium) and potassium hexoferrocyanate (HFC) was purchased from Sigma-Aldrich. SNP and HFC were dissolved in water at a concentration of $200 \mathrm{mM}$. C24-ceramide was synthetized by Biomol research laboratories (Plymouth, PA, USA). C24-ceramide was dissolved in ethanol/dodecan $(98 / 2, \mathrm{v} / \mathrm{v})$ at a concentration of $0.1 \mathrm{mM}$. Interleukin- $1 \beta$ (IL-1 $\beta$ ) was obtained from R\&D systems (Minneapolis, MN, USA). IL-1 $\beta$ was dissolved in PBS containing $1 \%$ fetal calf serum (FCS, BioWhittaker) at a concentration of $10 \mu \mathrm{g} / \mathrm{ml}$.

\subsection{Osteoblast cell culture}

MC3T3-E1 is a non-transformed mouse osteoblastic cell line (DSMZ, ACC 210, Brawnschweig, Germany). Cells were cultured in $\alpha$-minimal essential medium $(\alpha-$ MEM BioWhittaker, Taufkirchen, Germany) supplemented with $10 \%$ FCS, penicillin $(100 \mathrm{IU} / \mathrm{ml})$ and streptomycin $(100 \mu \mathrm{g} / \mathrm{ml})$ in a humidified incubator at $37^{\circ} \mathrm{C}$ with $5 \% \mathrm{CO}_{2}$. Only MC3T3-E1 cells that had undergone less than 15 passages were used. For all experiments,
MC3T3-E1 cells were plated in phenol-red free $\alpha$-MEM (BioWhittaker) supplemented with $1 \%$ charcoal-treated FCS, penicillin $(100 \mathrm{IU} / \mathrm{ml})$ and streptomycin $(100 \mu \mathrm{g} /$ $\mathrm{ml})$. MC3T3-E1 cells were seeded at the following densities: $10^{4}$ cells/well in flat bottomed 96-well plates (Falcon, VWR scientific products, Leuven, Belgium) for determination of cellular viability, $2.8 \times 10^{5}$ cells/well in 6-well plates for trypan blue exclusion, for IL-6 measurement and for transfection experiments; $4 \times 10^{6}$ cells in $143 \mathrm{~cm}^{2}$ dishes for determination of intracellular ceramide levels; and $2 \times 10^{5}$ cells/chamber in eight chamber slides for cytochemical staining. Cells were treated with either SNP (1-4 mM), HFC (2-3 mM) or C24-ceramide $(0.5-1 \mu \mathrm{M})$ as indicated in the text and legends. An equal amount of solvent was added to control cultures. For establishing effect of estrogen and SERMs, cells were pretreated with either raloxifene, $17 \beta-$ estradiol, tamoxifen or ICI 182.780, all at concentrations from $10^{-10}$ to $10^{-6} \mathrm{M}$, for $48 \mathrm{~h}$ before treatment with control media, SNP, C24-ceramide as indicated in the text and legends. An equal amount of solvent was added to control cultures. For raloxifene $\left(10^{-6} \mathrm{M}\right)$ and $17 \beta$-estradiol $\left(10^{-6} \mathrm{M}\right)$ effects on IL-6 protein levels and promoter activity, cells were pretreated with raloxifene or $17 \beta$-estradiol for $48 \mathrm{~h}$ before treatment with IL$1 \beta(10 \mathrm{ng} / \mathrm{ml})$ for $1-24 \mathrm{~h}$ as indicated in the text and legends.

\subsection{MTS reduction assay}

Cell viability was assessed by reduction of the yellow tetrazolium salt 3-(4.5-dimethylthiazol-2-yl)-5-(3-carboxymethoxyphenyl)-2-(4-sulfophenyl)-2H-tetrazolium (MTS) to the blue formazan product by mitochondrial enzymes in viable cells (colorimetric proliferation assay: "Cell Titer 96 Aqueous ${ }^{\circledR}$ " Promega, Leiden, The Netherlands). At the end of the treatment period, $20 \mu \mathrm{l}$ of MTS/ PMS solution was added to each well. The reactions were incubated for $2 \mathrm{~h}$ at $37^{\circ} \mathrm{C}$ in a humidified atmosphere of $5 \% \mathrm{CO}_{2}$. Absorbance was then measured at $492 \mathrm{~nm}$ with a Titertek Multiskan ${ }^{\circledR}$ Plus MK II (Flow laboratories, Brussels, Belgium) and the data were expressed as a percentage of levels of untreated control cells.

\subsection{Trypan blue exclusion}

After treatment, adherent cells were detached by treatment with trypsin (BioWhittaker), according to standard procedures. Floating cells were collected by centrifugation of the medium. Adherent and floating cells were pooled and resuspended in FCS-containing medium, mixed with four equal volumes of trypan blue solution and then counted and scored for dye exclusion. Results are expressed as percent viability, which was calculated as $100 \times$ (number of viable cells/number of total cells per well). 


\subsection{Nitrite analysis in conditioned medium}

For quantitative analysis of $\mathrm{NO}_{2}^{-}$in conditioned medium (CM), triplicate aliquots $(100 \mu \mathrm{l})$ of $\mathrm{CM}$ or nitrite standards $\left(\mathrm{NaNO}_{2}\right)$ were mixed with $100 \mu \mathrm{l}$ of Griess reagent $(2 \%$ sulfanilamide in $5 \%$ phosphoric acid and $0.2 \% N$-(1-naphtyl)ethylene-diamine) in 96-well plates. Absorbance was measured at $560 \mathrm{~nm}$ after $10 \mathrm{~min}$ with a Titertek Multiskan ${ }^{\circledR}$ Plus MK II (Flow Laboratories).

\subsection{Measurement of intracellular ceramide levels}

Liquid chromatography-electrospray ionization tandem mass spectrometry (LC-ESI-MS/MS) was used to measure intracellular ceramide levels as described previously [16]. Standard solutions for optimization of LC-ESI-MS/MS were prepared by dissolving ceramides in a 99.8/0.2 (v/v) mixture of ethanol/formic acid to reach a concentration of $1 \mu \mathrm{g} / \mathrm{ml}$. For extraction of cellular lipids, cells were rinsed twice with ice-cold PBS, then scraped in PBS and centrifuged at $800 \times g$. The resulting pellet was homogenized in distilled water by sonication. An aliquot of the cell homogenate was reserved for determination of protein levels. Ten nanograms of C12-ceramide (as an internal standard) was added to samples of cell lysates containing $300 \mu \mathrm{g}$ of protein. Lipids were extracted using Folch's partition with a mixture of chloroform and methanol (2/1, v/v). Samples were then centrifuged at $1500 \times g$ and washed with chloroform, methanol and water $(5 / 48 / 47, v / v / v)$. The organic phase was evaporated to near dryness under a gentle stream of dry nitrogen. The samples were reconstituted by vortexing with $100 \mu \mathrm{l}$ of a mixture of ethanol/formic acid (99.8/0.2) until they were completely dissolved. To avoid any loss of lipids, the entire procedure was performed in siliconized glassware. The LC-ESI-MS/MS procedure we use detects endogenous ceramides C14, C16, C18, C20, C22 and C24 [16]. C22- and C24-ceramides levels illustrated are representative of at least three distinct experiments.

\subsection{Estrogen receptor mRNA levels}

Estrogen receptor (ER) $\alpha$ and $\beta$ mRNA levels were determined using reverse-transcriptase-polymerase chain reaction amplification (RT-PCR) [17]. Total RNA was extracted from MC3T3-E1 cells using RNeasy columns from Qiagen (Valencia, CA, USA), according to the manufacturer's instructions. Recovered RNA was quantified by spectrometry (Gene Quant, Pharmacia, Peapack, NJ, USA), and $1 \mu \mathrm{g}$ of RNA was subjected to reverse transcription using the First strand cDNA synthesis kit for RTPCR (Roche, Mannheim, Germany). The newly transcribed cDNA was amplified by PCR as previously described [17] in the presence of the following primers: $\mathrm{ER} \alpha$ (accession no. M38651) sense, 5'-AATTCTGACAATCGACGCCAG-3'; antisense, 5'-GTGCTTCAACATTCTCCCTCCTC-3'; ER $\beta$ (accession no. U81451) sense, $5^{\prime}$-AAAGCCAAGAGAACCAGTGGGCAC- $3^{\prime}$; anti sense, 5'-GCCAATCATGTGCACCAGTTCCTT-3'. The expression of each transcript was normalized to $\beta$-actin (accession no. X03672). For $\beta$-actin, 32 cycles of PCR $\left(94{ }^{\circ} \mathrm{C}\right.$ for $30 \mathrm{~s}, 61{ }^{\circ} \mathrm{C}$ for $30 \mathrm{~s}, 72{ }^{\circ} \mathrm{C}$ for $30 \mathrm{~s}$ ) were performed in the presence of the sense $5^{\prime}$-CATGTGCAAGGCCGGCTTCG- $3^{\prime}$ primer and the antisense $5^{\prime}$ GGCCTCGGTGAGCAGCACAG-3' primer. For negative control the RT step was omitted before the PCR. Products were separated by 3\% agarose gel electrophoresis and visualized by ethidium bromide staining.

\subsection{Estrogen receptor protein levels}

Estrogen receptor protein levels were estimated by Western immunoblot as previously described [18]. Briefly, $10 \mu \mathrm{g}$ of proteins were fractionated by electrophoresis on a $10 \%$ polyacrylamide gel. Proteins were transferred onto an Immobilon ${ }^{\mathrm{TM}} \mathrm{P}$ transfer membrane (Millipore, Bedford, MA, USA). Membranes were blocked with Tris-buffered saline-Tween $(20 \mathrm{mM}$ Tris $\mathrm{pH} 7.5,500 \mathrm{mM} \mathrm{NaCl}, 0.2 \%$ Tween) plus $5 \%$ dry milk before incubation for $3 \mathrm{~h}$ with an anti-ER $\alpha$ or an anti-ER $\beta$ antibody (sc-7207 and sc-8974 both from Santa Cruz Biotechnology, Santa Cruz, CA, USA) diluted at 1:1000.

Horseradish peroxidase-linked anti-rabbit antibodies (DakoCytomation, Glostrup, Denmark) were used as secondary antibodies for analysis of ER $\alpha$ and ER $\beta$. The reaction was revealed with the enhanced chemiluminescence detection reagent according to the instructions of the manufacturer (ECL kit, Amersham Pharmacia Biotech UK Limited, Buckinghamshire, UK). Western blots illustrated are representative of at least two distinct experiments.

\subsection{Determination of apoptosis by cytochemical staining}

The presence of apoptotic cells was determined by fluorescent microscopy [19]. After treatment, cells were washed with PBS and $100 \mu \mathrm{l}$ of HEPES buffer per slide (10 mM HEPES/NaOH, pH 7.4, $140 \mathrm{mM} \mathrm{NaCl}, 5 \mathrm{mM}$ $\left.\mathrm{CaCl}_{2}\right)$ with propidium iodide $(0.5 \mu \mathrm{l}$ per $100 \mu \mathrm{l}$ of buffer $)$ and Annexin-V (Annexin-V FLUOS Staining kit, Roche, Manheim, Germany, $0.5 \mu l$ per $100 \mu$ l of buffer). Cells were incubated for $15 \mathrm{~min}$ at room temperature and immediately visualized under fluorescent microscopy. Annexin$\mathrm{V}$ (green) is a marker of apoptosis and propidium iodide (red) reflects the integrity of the cell membrane, thereby serving as a marker of necrosis [19].

\subsection{IL-6 protein measurement}

Conditioned media were collected from MC3T3-E1 cells treated with IL-1 $\beta$. Mouse IL-6 protein levels were measured by ELISA according to the manufacturer's instructions (R\&D systems, Abington, UK). The IL-6 assay has a lower limit of detection of $3,1 \mathrm{pg} / \mathrm{ml}$. All 
values were corrected for cell number. The data were expressed as a percentage of the control cultures.

\subsection{Transient transfections}

MC3T3-E1 cells were transfected with $1 \mu \mathrm{g}$ of chimeric construct of the five flanking region of the rat IL- 6 promoter $(-2904$ to +30$)$ and the luciferase reporter gene (kindly provided by Dr. G. Fey, Friedrich-Alexander Universität, Erlangen, Germany) using Fugene reagent (Roche) with a 1:4 DNA/Fugene ratio, according to the manufacturer's instructions [20]. Cotransfection with a construct containing RSV promoter-driven $\beta$-galactosidase gene (kindly provided by Dr. R. Winkler, University of Liege, Liege, Belgium) was used to control transfection efficiency. After a $4 \mathrm{~h}$ recovery period, cells were transferred in phenol-red free $\alpha$-MEM supplemented with $10 \%$ charcoal-treated FCS for $24 \mathrm{~h}$ before treatment with various agents as described in the legends. The cells were washed with phosphate buffered saline and harvested in lysis buffer ( $\beta$-GAL reporter gene assay chemiluminescent, Roche). Luciferase activity was measured using a luciferase reporter gene assay kit (Roche) and $\beta$-galactosidase activity using the $\beta$-GAL reporter gene assay chemiluminescent (Roche) both in accordance with manufacturer's instructions. All data were expressed as a percentage of levels of luciferase units/ $\beta$-galactosidase units normalized to control cells.

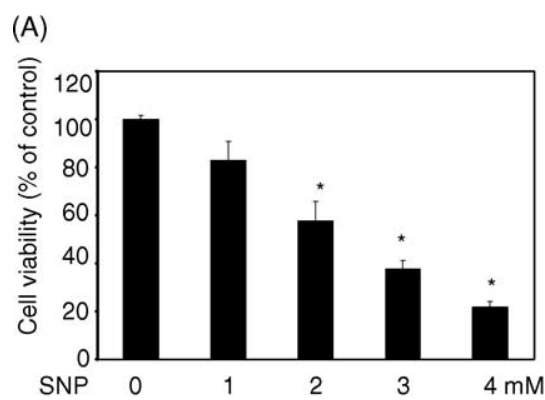

(C)

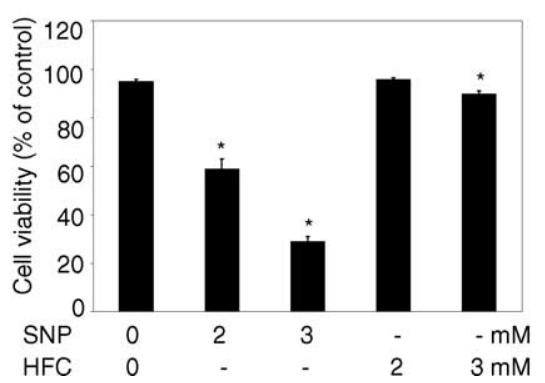

\subsection{Statistical analysis}

Data are presented as mean values \pm S.E.M. Data were analyzed by the Mann-Whitney test.

\section{Results}

\subsection{Cytotoxicity of SNP and HFC}

Increasing concentrations of SNP, a NO-donor, dosedependently decreased MC3T3-E1 cell viability after $24 \mathrm{~h}$ as determined by the MTS reduction assay (Fig. 1A) and increased NO release in the culture media of osteoblastic cells in a time-dependent manner (Fig. 1B). Unlike other NO donors, SNP contains iron cyanide in addition to nitric oxide [21]. To determine whether SNP-induced MC3T3E1 cell death is NO-dependent, we studied the effect of potassium hexoferrocyanide (HFC), a molecule that has a similar structure as SNP but does not induce NO production [21]. HFC only slightly decreased cell viability. At a concentration of $3 \mathrm{mM}$, HFC decreased MC3T3-E1 cell viability by $10 \%$, whereas $3 \mathrm{mM}$ SNP induced a $71 \%$ decrease in MC3T3-E1 cell viability after $24 \mathrm{~h}$ (Fig. 1C), suggesting that NO release is required for SNP-induced cell death. This is consistent with previous reports demonstrating that high NO levels induce osteoblastic cell death $[6,7]$.

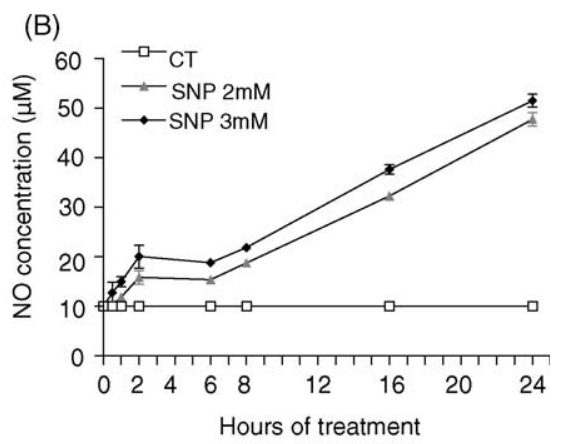

Fig. 1. Sodium nitroprusside (SNP) vs. potassium hexoferrocyanate (HFC) cytotoxicity. (A) MC3T3-E1 cells were treated with SNP for 24 h at the indicated concentrations. Cell viability was measured with the MTS reduction assay. Data are expressed as average percentage of control levels \pm S.E.M. in 11 samples

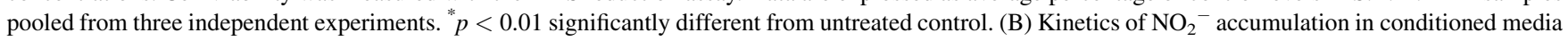
of MC3T3-E1 cells. $\mathrm{NO}_{2}{ }^{-}$levels were measured by the Griess assay after MC3T3-E1 cells were treated with control media or SNP for various times from 0 to $24 \mathrm{~h}$, as indicated. Data are expressed as the average NO concentration $(\mu \mathrm{M}) \pm$ S.E.M. of 12 samples pooled from three independent experiments. (C) MC3T3E1 cells were treated with SNP or HFC at 2 or $3 \mathrm{mM}$ for $24 \mathrm{~h}$. Cell viability was measured by the trypan blue exclusion test. Data are expressed as average percentage of control levels \pm S.E.M. of 12 samples pooled from two independent experiments. * $p<0.05$ significantly different from untreated control. 
(A)
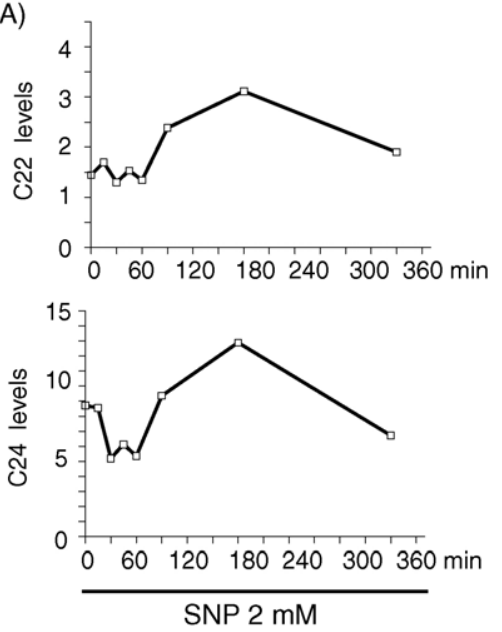

(B)

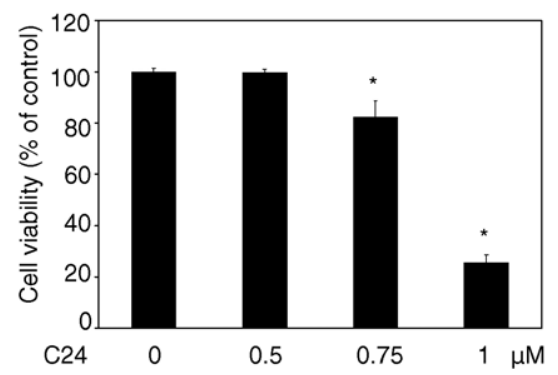

Fig. 2. SNP effect on intracellular ceramide levels and cytotoxicity of C24ceramide. (A) Kinetics of the intracellular accumulation of C22- and C24ceramide in MC3T3-E1 cells treated with SNP. MC3T3-E1 cells were treated with $2 \mathrm{mM} \mathrm{SNP}$ for 0 to $360 \mathrm{~min}$, as indicated. Ceramide levels were then measured by LC-ESI-MS/MS. Values corresponding to the intracellular ceramide peak area were divided by the internal standard peak area. One representative experiment is shown. (B) MC3T3-E1 cells were treated with $\mathrm{C} 24$-ceramide for $24 \mathrm{~h}$ at the indicated concentrations. Cell viability was measured with the MTS reduction assay. Data are expressed as average percentage of control \pm S.E.M. of 8 samples pooled from two independent experiments. ${ }^{*} p<0.05$ significantly different from untreated control.

\subsection{Intracellular ceramide levels after SNP treatment}

Ceramides are second messengers of apoptosis [22,23]. To determine the role of ceramides in cell death induced by NO donors, we measured the intracellular levels of ceramides C14-C24 by liquid chromatography-coupled electrospray ionization tandem mass spectrometry (LC-ESIMS/MS). Fig. 2A shows that C22- and C24-ceramide levels increased significantly $3 \mathrm{~h}$ after SNP treatment. Intracellular C24 levels were higher than C22 levels at baseline, but the concentrations of both $\mathrm{C} 22$ and $\mathrm{C} 24$ were increased by up to $170 \%$ of control levels after SNP treatment (Fig. 2A). C14, C16, C18 and C20 ceramide levels were unaffected by the presence of SNP (data not shown). To further establish if C24-ceramide induces osteoblastic cell death directly, MC3T3-E1 cells were treated with synthetic C24-ceramide (Fig. 2B). Osteoblastic cell viability was decreased by $18 \%$ and $74 \%$ in the presence of 0.75 and $1 \mu \mathrm{M} \mathrm{C} 24$, respectively (Fig. 2B),
(A)

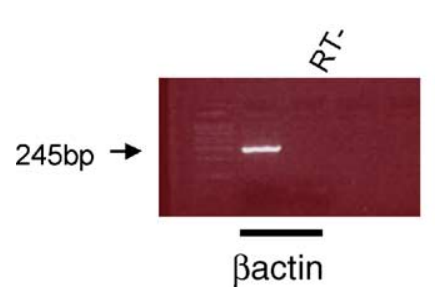

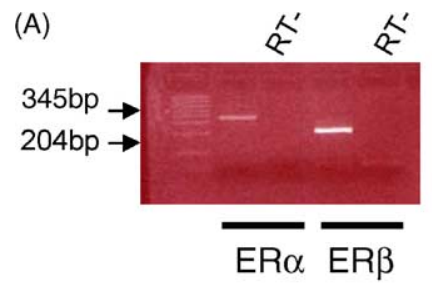

(B)
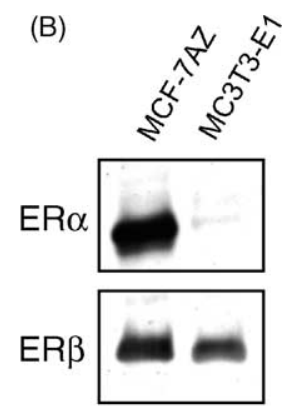

Fig. 3. Levels of $E R \alpha$ and $E R \beta$ in osteoblastic cells. (A) Estrogen receptors transcripts by RT-PCR in MC3T3-E1 osteoblastic cells. The 345 bp fragment of ER $\alpha$ and $204 \mathrm{bp}$ fragment of ER $\beta$ are illustrated in the upper panel and the $245 \mathrm{bp}$ fragment of $\beta$-actin from the same RT sample is shown in the lower panel. No message was identified when the RT step was omitted $(\mathrm{RT}-)$. (B) Estrogen receptors protein levels by Western blotting. Total cellular extracts from MC3T3-E1 and human breast cancer MCF7-AZ (positive control) cells were analyzed by Western immunoblot analysis. $\mathrm{ER} \alpha$ protein was detected by an anti-ER $\alpha$ antibody and is illustrated in the upper panel. ER $\beta$ protein was detected by an anti-ER $\beta$ antibody and is illustrated in the lower panel.

indicating that $\mathrm{C} 24$ is possibly one of the mediators of SNP induced cell death.

\subsection{Estrogen receptor (ER $\alpha$ and $E R \beta) m R N A$ and protein levels}

To study the effects of estrogenic compounds on NOinduced MC3T3-E1 cell death, we first investigated whether these cells express ER. For this purpose, we evaluated by RT-PCR and Western blotting cellular levels of the two ER isoforms in MC3T3-E1 cells. Confirming previous results, MC3T3-E1 cells expressed ER $\alpha$ and ER $\beta$ transcripts (Fig. 3A). However at the protein level, while MC3T3-E1 osteoblastic cells expressed ER $\beta$, the level of $\mathrm{ER} \alpha$ was barely detectable in accordance to previous observations of a wide variation of ER protein expression in these cells (Fig. 3B) [17].

\subsection{Effects of raloxifene, $17 \beta$-estradiol, tamoxifen and ICI 182.780 on SNP-induced cytotoxicity}

Previous studies demonstrated a potent anti-apoptotic effect of estrogens on osteoblastic cells [10]. We thus compared the effect of $17 \beta$-estradiol with two SERMs, raloxifene and tamoxifen, and a pure estrogen antagonist, ICI 182.780, on osteoblastic cell death induced by SNP. Pretreatment of MC3T3-E1 cells with raloxifene at doses of $10^{-10}, 10^{-7}$ and $10^{-6} \mathrm{M}$ for $48 \mathrm{~h}$ prior to the addition of SNP decreased osteoblast cell death, whereas $17 \beta$-estradiol or ICI 182.780 did not have any significant effect (Fig. 4A). The SERM tamoxifen had similar protective 
(A)
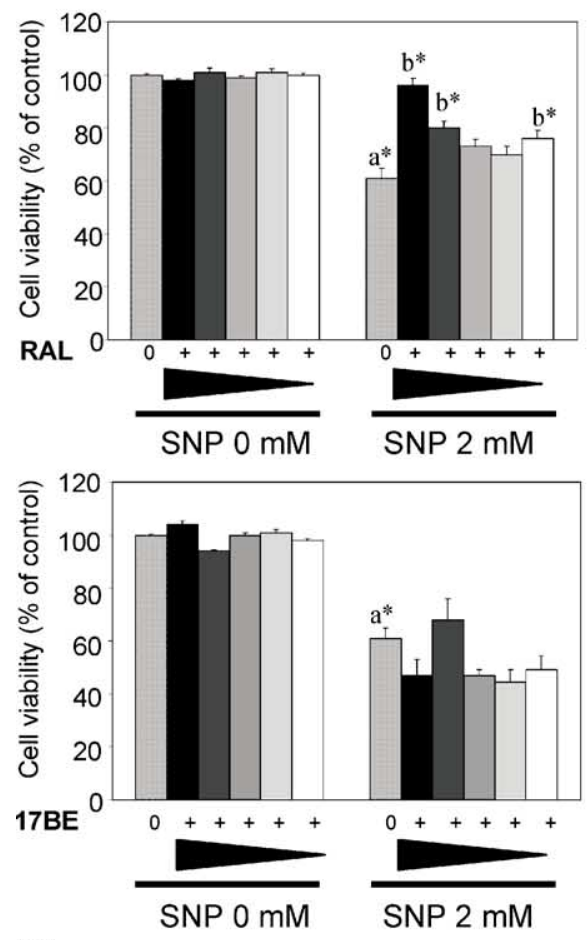

(B)

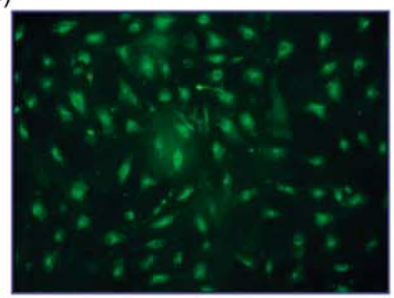

SNP $2 \mathrm{mM}$
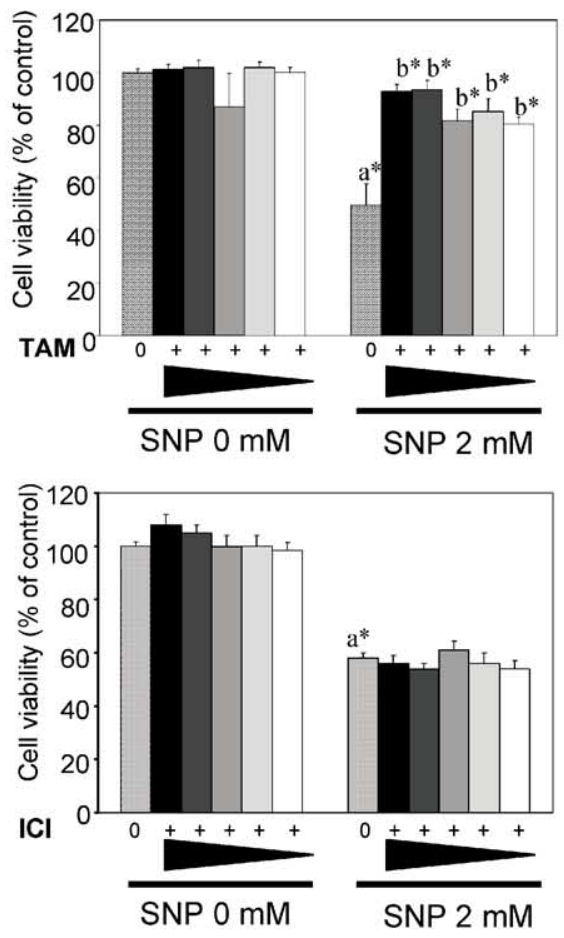

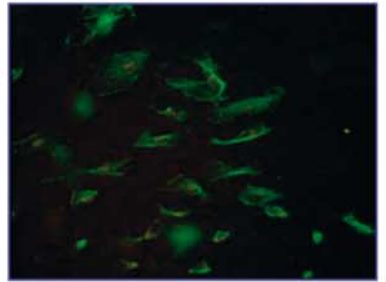

BE/ SNP 2mM

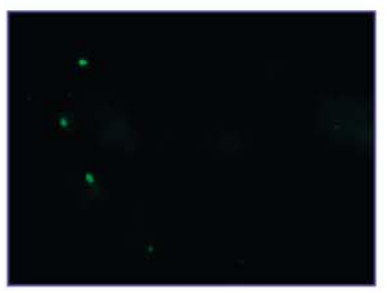

RAL/SNP 2mM

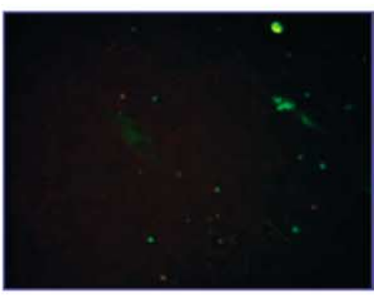

TAM/ SNP 2mM

Fig. 4. Effects of raloxifene, $17 \beta$-estradiol, tamoxifen and ICI 182.780 on SNP-induced cell death. (A) Cell viability was measured with the MTS reduction assay. MC3T3-E1 cells were pretreated with control media (0) or raloxifene (RAL), 17ß-estradiol (17BE), tamoxifen (TAM) or ICI 182.780 (ICI) at decreasing concentrations $\left(10^{-6}, 10^{-7}, 10^{-8}, 10^{-9}\right.$ or $\left.10^{-10} \mathrm{M}\right)$ for $48 \mathrm{~h}$ and treated in the presence or absence of $2 \mathrm{mM}$ SNP for an additional $24 \mathrm{~h}$. Data are expressed as average percentage of control levels \pm S.E.M. of 8 samples pooled from two independent experiments. $\left(\mathrm{a}^{*}\right) p<0.01$ significantly different from untreated control and $\left(\mathrm{b}^{*}\right) p<0.05$ significantly different from SNP-treated cultures. (B) Fluorescence staining of MC3T3-E1 in the presence of SNP. Effect of raloxifene, $17 \beta$-estradiol, tamoxifen or ICI 182.780 on MC3T3-E1 apoptosis. MC3T3-E1 cells were pretreated with control media (CT) or raloxifene (RAL), 17 $\beta$-estradiol (17BE), tamoxifen (TAM) or ICI 182.780 (ICI) at $10^{-6} \mathrm{M}$ for $48 \mathrm{~h}$ prior to treatment with $2 \mathrm{mM}$ SNP for an additional $16 \mathrm{~h}$. After treatment, cells were labeled with Annexin-V coupled to fluorescein and propidium iodide. Cells were then examined fluorescence microscopy. The photomicrographs show apoptotic cells labeled by Annexin-V.

effects as raloxifene on the survival of MC3T3-E1 mouse osteoblastic cells at concentrations from $10^{-10}$ to $10^{-6} \mathrm{M}$ (Fig. 4A). These results suggest that the protective effects of raloxifene and tamoxifen on osteoblast cell death are representative of this class of medication (SERMs).

To confirm that SNP induced osteoblast cell death by apoptosis, MC3T3-E1 cells were analyzed by fluorescence staining with Annexin- $\mathrm{V}$ and propidium iodide (A/PI) (Fig. 4B) [19]. In the presence of SNP, MC3T3-E1 cells were labeled primarily by Annexin-V, indicating that SNPinduced cell death occurred by apoptosis. Pretreatment with raloxifene or tamoxifen but not by $17 \beta$-estradiol or ICI 182.780 induced a decrease in Annexin-V labeling after treatment with SNP (Fig. 4B), which is consistent 

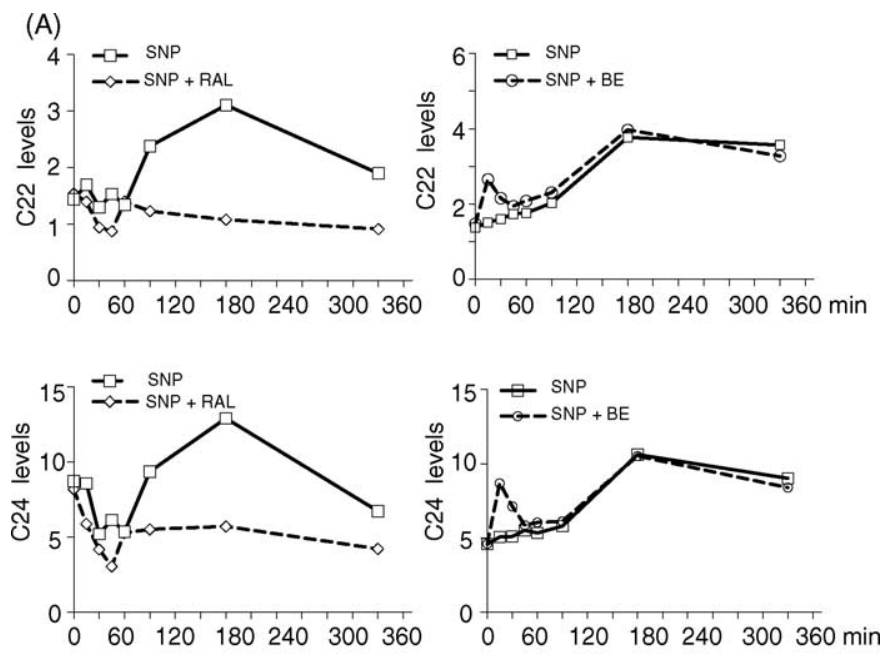

(B)

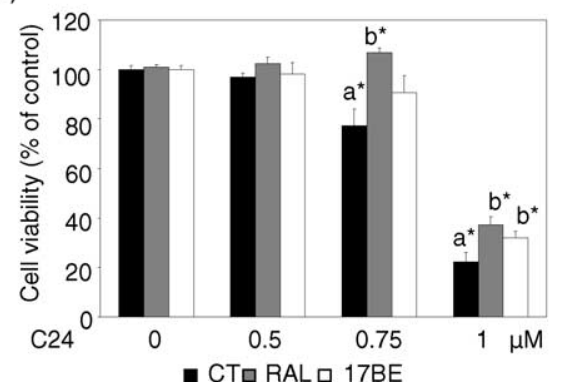

Fig. 5. Raloxifene effect on SNP-induced ceramide levels and on C24-ceramide-induced cell death. (A) Kinetics of the intracellular accumulation of C22- and C24-ceramide in MC3T3-E1 cells pretreated with raloxifene or 17 $\beta$-estradiol. MC3T3-E1 cells were pretreated with control media, raloxifene or 173-estradiol at $10^{-6} \mathrm{M}$ for $48 \mathrm{~h}$ prior to treatment with $2 \mathrm{mM} \mathrm{SNP}$ for 0 to $360 \mathrm{~min}$, as indicated. Ceramide levels were then measured by LC-ESI-MS/MS. Values corresponding to the intracellular ceramide peak area were divided by the internal standard peak area. One representative experiment is shown. (B) MC3T3-E1 cells were pretreated with control media, raloxifene or $17 \beta$-estradiol at $10^{-6} \mathrm{M}$ for $48 \mathrm{~h}$ prior to treatment with $\mathrm{C} 24$-ceramide for $24 \mathrm{~h}$ at the indicated concentrations. Cell viability was measured with the MTS reduction assay. Data are expressed as average percentage of control \pm S.E.M. of 8 samples pooled from two independent experiments. $\left(\mathrm{a}^{*}\right) p<0.01$ significantly different from untreated control and $\left(\mathrm{b}^{*}\right) p<0.05$ significantly different from $\mathrm{C} 24$-ceramidetreated cultures.

with the MTS data (Fig. 4A). We confirmed that cell cultures were at similar confluences (data not shown).

\subsection{Comparative effects of raloxifene and $17 \beta$-estradiol on SNP-induced ceramide levels and C24-ceramide- induced cell death}

The induction of C22- and C24-ceramide levels by SNP was decreased when the cells were pretreated with $10^{-6} \mathrm{M}$ raloxifene $48 \mathrm{~h}$ prior to the addition of SNP at $2 \mathrm{mM}$ (Fig. 5A), but treatment with $17 \beta$-estradiol at the same concentration had no effect on C22- and C24ceramide levels (Fig. 5A). As exogenous C24-ceramide could induce osteoblastic cytotoxicity (Fig. 2B), we also tested if raloxifene protected MC3T3-E1 cells from C24ceramide-induced cell death. Fig. 5B shows that cell viability was maintained at control levels when osteoblasts were pretreated with raloxifene at $10^{-6} \mathrm{M}$ prior to treatment with $0.75 \mu \mathrm{M} \mathrm{C} 24$-ceramide. In the presence of C24-ceramide at $1 \mu \mathrm{M}$, a marked decrease in cell viability was observed but raloxifene and $17 \beta$-estra- diol only weakly prevented cell death (Fig. 5B). All together these data suggest that the long chain ceramide C24 is a mediator of SNP-induced osteoblastic cell death and that raloxifene exerts its protective effect by decreasing ceramide production. However, a partial protection against ceramide-induced cytotoxicity could not be excluded.

\subsection{Comparative effects of raloxifene and $17 \beta$-estradiol on IL-6 protein synthesis and promoter activity}

As $17 \beta$-estradiol had no significant effect on SNPinduced MC3T3-E1 cell death, we next verified a relevant $17 \beta$-estradiol effect in these cells. For this purpose, we studied the effect of $17 \beta$-estradiol and raloxifene on IL-6, a cytokine known to be inhibited by these two anti-resorptive agents [24,25]. IL-6 levels were undetectable in control cultures (data not shown) but were markedly enhanced in the presence of IL- $1 \beta$ at $10 \mathrm{ng} / \mathrm{ml}$ for $24 \mathrm{~h}$. Pretreatment of MC3T3-E1 cells with raloxifene or $17 \beta$-estradiol at $10^{-6} \mathrm{M}$ for $24 \mathrm{~h}$ prior to the addition of IL- $1 \beta$ inhibited 
(A)

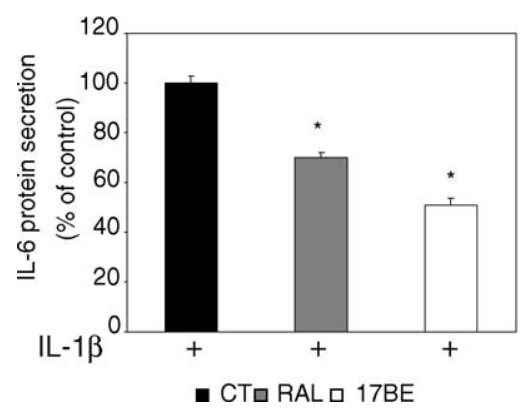

(B)

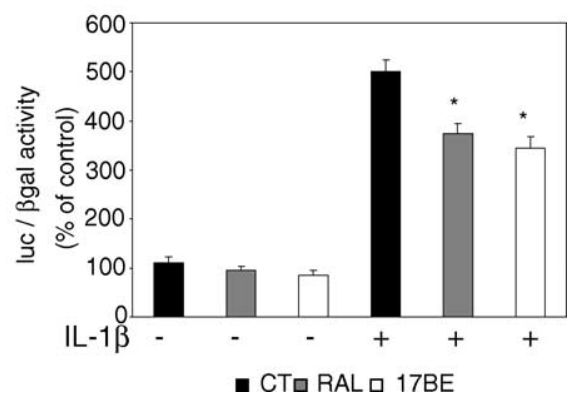

Fig. 6. Raloxifene and $17 \beta$-estradiol effects on IL-6 protein levels and promoter activity. (A) IL-6 protein levels were measured by ELISA from conditioned medium harvested from MC3T3-E1 cells pretreated with control media, raloxifene or $17 \beta$-estradiol at $10^{-6} \mathrm{M}$ for $24 \mathrm{~h}$ prior to treatment with IL-1 $\beta$ at $10 \mathrm{ng} / \mathrm{ml}$ for $24 \mathrm{~h}$. Data are expressed as percentage of IL-1 $\beta$ treated cells (control) \pm S.E.M. of 12 samples pooled from four independent experiments. ${ }^{*} p<0.01$ significantly different from control. (B) MC3T3-E1 cells were transfected with a chimeric constructs containing the rat IL-6 promoter sequence linked to a luciferase reporter gene. To control for transfection efficiency, a RSV- $\beta$-galactosidase vector was co-transfected. Twenty-four hours post-transfection, MC3T3E1 cells were pretreated with control media, raloxifene or $17 \beta$-estradiol at $10^{-6} \mathrm{M}$ for $24 \mathrm{~h}$ prior to treatment with IL- $1 \beta$ at $10 \mathrm{ng} / \mathrm{ml}$ for $1 \mathrm{~h}$. Data are expressed as percentage of control \pm S.E.M. of 9 samples pooled from three independent experiments. ${ }^{*} p<0.01$ significantly different from IL-1 $\beta$ treated cultures.

IL-6 protein by $30 \%$ and $49 \%$, respectively (Fig. 6A). We also verified that $17 \beta$-estradiol had genomic effect on IL-6 reporter gene [10] by transiently transfecting MC3T3-E1 with a chimeric constructs of the rat IL-6 promoter and the luciferase gene. Fig. 6B shows that IL-6 promoter activity was increased by IL- $1 \beta$ and that this effect was inhibited by pretreatment of osteoblastic cells with $17 \beta$-estradiol and raloxifene at $10^{-6} \mathrm{M}$.

\section{Discussion}

Nitric oxide mediates numerous biological process. NO induces a cytotoxic activity against tumor cells. In bone, stimulation of NO production in inflammatory diseases was also associated with bone loss and osteoblast apoptosis. This report confirmed that high NO levels induced apoptosis of osteoblastic cells. To study this effect, we treated MC3T3-E1 with an exogenous NO-releasing compound, SNP, and demonstrated that NO release was required for osteoblast cell death. We further determined the mechanisms by which SNP induces apoptosis in osteoblasts by evaluating intracellular ceramide levels. Ceramides are intracellular second messengers involved in stress and cell death [26-29]. Several groups have previously demonstrated that NO up-regulates intracellular ceramide levels in various cell types and suggested that this increase was involved in apoptosis [30,31]. However to date, there were little informations about the function of different ceramide species. A few reports suggested that very long chain ceramides were generated during growth arrest and apoptosis but there were no studies on the differential regulation of ceramide species by NO [3234]. Our data show that the intracellular levels of the ceramides $\mathrm{C} 22$ and $\mathrm{C} 24$ increased after treatment of MC3T3-E1 osteoblastic cells with SNP. Moreover, we confirmed that $\mathrm{C} 24$-ceramide and $\mathrm{C} 20$-ceramide (data not shown) decreased MC3T3-E1 cell viability, demon- strating that the long chain ceramides are able to induce osteoblastic cell death.

Previous reports revealed the role of NO in bone remodeling and demonstrated its involvement in the pathophysiology of osteoporosis [8]. Consequently, we tested whether estrogenic compounds could influence NOinduced apoptosis in osteoblasts. Estrogens decrease bone resorption but also influence osteoblast apoptosis [10]. Moreover, a decrease in circulating levels of estrogens remains the major cause of increased bone turnover in postmenopausal women and for many years, estrogen replacement therapy was considered to be the optimal prevention treatment for osteoporosis [35]. SERMs exhibit a combination of estrogen agonistic and antagonistic properties and might therefore provide a similar bone effect together with a better safety on the breast and uterus tissues. In the multiple outcomes of raloxifene evaluation (MORE) study, raloxifene was shown to significantly decrease the risk of new vertebral fractures after 3 and 4 years of treatment $[6,7]$ and raloxifene is now used for the treatment of post-menopausal osteoporosis. In parallel to its antiresorptive effect, raloxifene increases the proliferation of osteoblasts and influence various osteoblastic functions but it is not presently known whether raloxifene affects osteoblast apoptosis [24,25,36,37]. In this study, we compared the effects of $17 \beta$-estradiol with the SERMs raloxifene and tamoxifen and the pure antagonist of estrogen ICI 182.780 on osteoblast apoptosis induced by SNP. Raloxifene inhibited osteoblast apoptosis at doses ranging from $10^{-10}$ to $10^{-6} \mathrm{M}$, suggesting that the anti-apoptotic effect of raloxifene might be pharmacologically relevant and related to its clinical activity. The SERM tamoxifen had similar effects as raloxifene on the survival of MC3T3E1 mouse osteoblastic cells, suggesting that the protective effect observed is representative of this class of medication. Interestingly in our model, $17 \beta$-estradiol did not protect osteoblasts from cell death whereas both $17 \beta-$ estradiol and raloxifene had similar effects on the inhibi- 
tion of IL-6 protein levels and IL-6 promoter activity induced by IL-1 $\beta$. IL- 6 inhibition by both $17 \beta$-estradiol and raloxifene confirms that both compounds have similar ER-mediated effect in MC3T3-E1 cells in accordance to previous work $[10,38]$. We showed that MC3T3-E1 cells express both transcript and protein for ER $\beta$ and to lesser extent for ER $\alpha$. A great variation in the cellular levels of steroid receptor seems to be a characteristic of these osteoblast-like cells [17]. Nevertheless, despite heterogeneity of ER expression in MC3T3-E1 cells and obvious difference in receptor density between single cells, we confirmed that $17 \beta$-estradiol is capable of exerting ERmediated genomic effect in these cells as demonstrated by an inhibition of IL-6 promoter activity.

In parallel to the decrease in SNP-induced cell death, raloxifene decreased the induction of $\mathrm{C} 22$ - and $\mathrm{C} 24-\mathrm{cer}-$ amide levels in response to SNP. In contrast, 17ß-estradiol did not modify the effects of SNP on intracellular ceramide levels. This suggests that the protective effect of raloxifene on NO-induced apoptosis in MC3T3-E1 cells could be mediated by downregulation of the ceramide production. Ceramides might be generated by an enzymatic or a nonenzymatic hydrolysis of sphingomyeline as well as by de novo synthesis by ceramide synthase. Interestingly, these pathways are linked to apoptosis as demonstrated by the defect in radiation-induced apoptosis in acid sphingomyelinase-deficient human lymphoblasts [39]. Previous studies have shown that high levels of NO lead to an increase in ceramide by a dual action of NO: on one hand, an activation of ceramide-generating sphingomyelinases and on the other hand, a degradation of the ceramidases [40]. Raloxifene might decrease SNP-induced ceramide levels by directly inhibiting sphingomyelinase activities or other enzymes involved in ceramide generation or by blocking ceramide degradation (Fig. 7). In parallel, raloxifene could exert a protective effect on exogenous ceramide-induced cell death. While $17 \beta$-estradiol had no cytoprotective effect in the presence of SNP, both $17 \beta$-estradiol and raloxifene decreased slightly $\mathrm{C} 24$ - and $\mathrm{C} 20$-ceramide (data not shown) cytotoxic effect. These results suggest that while raloxifene and $17 \beta$-estradiol might moderately influence the signaling pathway activated downstream of the ceramide, the discrepancy between these two drugs on SNP-induced apoptosis should result from distinct effects on ceramide generation (i.e. ceramide synthesis or degradation) (Fig. 7).

Based on our current results, it is difficult to determine if raloxifene influences ceramide generation by a genomic or a non-genomic effect. It is tempting to postulate that the effect of raloxifene on ceramide release occurs at the membrane as membrane-bound ERs have been described in osteoblasts and as ceramide formation is taking place in the plasma membrane [28,41]. However, non-transcriptional effects are classically rapid and non-compatible with RNA and protein synthesis [41]. In our study, raloxifene pretreatment for $48 \mathrm{~h}$ was necessary to observe a protective

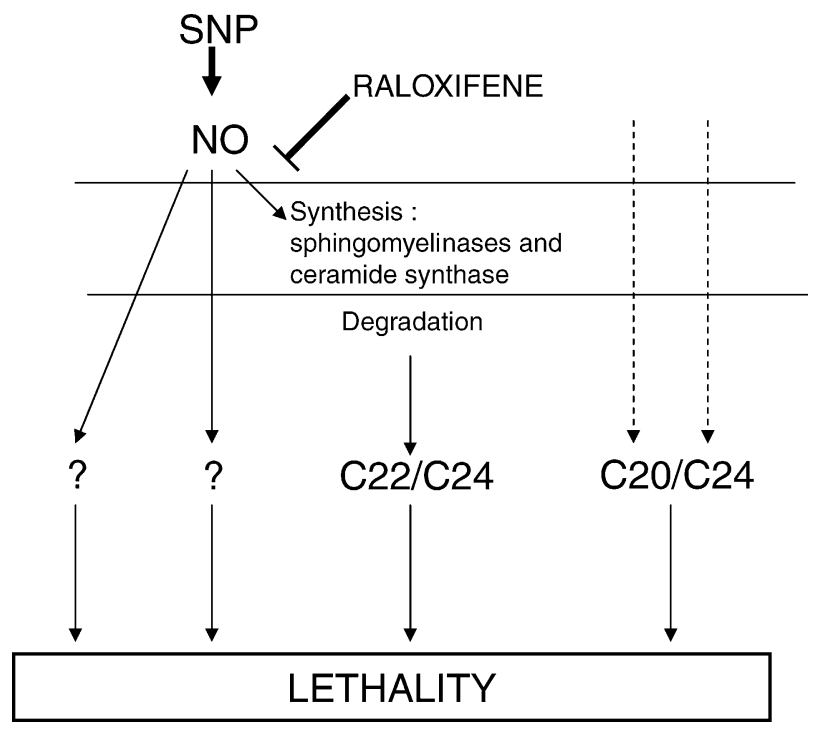

Fig. 7. Raloxifene and $17 \beta$-estradiol effects on osteoblastic cell death induced by NO and ceramides. One of the NO apoptotic pathways is mediated by ceramide generation. Raloxifene decreases the levels of intracellular C22- and C24-ceramides most likely by inhibiting ceramide synthesis or by influencing their degradation.

effect on SNP-induced cell death, indicating that de novo protein synthesis might be required and that non-genomic effects are unlikely. On the other hand, one might not exclude a non ER-mediated effect on ceramide generation as it is known that $17 \beta$-estradiol and tamoxifen might influence perturbations of membrane fluidity of human breast cancer cells [42]. These types of effects are usually observed with high doses of steroids. Concerning genomic effects, differences between estrogens and raloxifene might be explained by the involvement of distinct nuclear mechanisms such as gene promoter elements and coregulatory proteins, or simply by the nature of the gene specifically regulated by estrogen or raloxifene [43-47]. Indeed, recent data obtained by microarray technology have shown that bone-related genes regulated by $17 \beta-$ estradiol or raloxifene were distinct [48]. Only 17-18\% of the genes regulated by $17 \beta$-estradiol were also regulated by raloxifene or tamoxifen in U2OS stably transfected with $\mathrm{ER} \alpha$ or ER $\beta$. Moreover, genes regulated by $17 \beta$-estradiol or SERMs were different if cells were transfected with $\mathrm{ER} \alpha$ or ER $\beta$, underlying the importance of the type and the level of the ER expressed in the type of cells studied [48]. It is therefore possible that genes controlling ceramide synthesis or degradation are specifically regulated by SERMs (i.e. and not by estrogen) via ER $\beta$ and/or ER $\alpha$ in MC3T3E1 cells.

In conclusion, raloxifene protects osteoblast from apoptosis induced by SNP through an inhibition of C22- and C24-ceramide generation. It is possible that the anti-apoptotic effect of raloxifene contributes to an improvement in bone quality predominantly under stressful conditions, as NO is released by bone cells in response to pro-inflammatory cytokines or mechanical strain. 


\section{Acknowledgments}

The authors are thankful to Dr. Fey and Dr. Winkler for providing the plasmid constructs. The authors thank Aline Desoroux and Simone Gaspar for expert technical assistance. S. Olivier thanks Dr. C. Ribbens and Dr. B. Relic for their kind advice. The authors thank Eli Lilly and Co. for providing raloxifene and for their kind help and discussion.

This work was supported by a TELEVIE grant from The Belgian National Funds for Scientific Research (FNRS). M. Fillet, M.P. Merville and N. Franchimont are Research Associates at the FNRS. J. Piette is Research Director at the FNRS.

\section{References}

[1] Ralston SH. Nitric oxide and bone: what a gas! Br J Rheumatol 1997;36:831-8.

[2] Mancini L, Moradi-Bidhendi N, Becherini L, Martineti V, MacIntyre I. The biphasic effects of nitric oxide in primary rat osteoblasts are cGMP dependent. Biochem Biophys Res Commun 2000;274:477-81.

[3] Damoulis PD, Hauschka PV. Nitric oxide acts in conjunction with proinflammatory cytokines to promote cell death in osteoblasts. J Bone Miner Res 1997;12:412-22.

[4] Lowik CW, Nibbering PH, van de Ruit M, Papapoulos SE. Inducible production of nitric oxide in osteoblast-like cells and in fetal mouse bone explants is associated with suppression of osteoclastic bone resorption. J Clin Invest 1994;93:1465-72.

[5] Ralston SH, Todd D, Helfrich M, Benjamin N, Grabowski PS. Human osteoblast-like cells produce nitric oxide and express inducible nitric oxide synthase. Endocrinology 1994;135:330-6.

[6] Klein-Nulend J, Helfrich MH, Sterck JG, MacPherson H, Joldersma $\mathrm{M}$, Ralston SH, et al. Nitric oxide response to shear stress by human bone cell cultures is endothelial nitric oxide synthase dependent. Biochem Biophys Res Commun 1998;250:108-14.

[7] Armour KE, Ralston SH. Estrogen upregulates endothelial constitutive nitric oxide synthase expression in human osteoblast-like cells. Endocrinology 1998;139:799-802.

[8] Armour KJ, Armour KE, van't Hof RJ, Reid DM, Wei XQ, Liew FY, et al. Activation of the inducible nitric oxide synthase pathway contributes to inflammation-induced osteoporosis by suppressing bone formation and causing osteoblast apoptosis. Arthritis Rheum 2001;44: 2790-6.

[9] Ji L, Zhang G, Uematsu S, Akahori Y, Hirabayashi Y. Induction of apoptotic DNA fragmentation and cell death by natural ceramide. FEBS Lett 1995;358:211-4.

[10] Kousteni S, Bellido T, Plotkin LI, O’Brien CA, Bodenner DL, Han L, et al. Nongenotropic, sex-nonspecific signaling through the estrogen or androgen receptors: dissociation from transcriptional activity. Cell 2001;104:719-30.

[11] Nuttall ME, Stroup GB, Fisher PW, Nadeau DP, Gowen M, Suva LJ. Distinct mechanisms of action of selective estrogen receptor modulators in breast and osteoblastic cells. Am J Physiol Cell Physiol 2000;279:C1550-1557.

[12] Ettinger B, Black DM, Mitlak BH, Knickerbocker RK, Nickelsen T, Genant HK, et al. Reduction of vertebral fracture risk in postmenopausal women with osteoporosis treated with raloxifene: results from a 3 -year randomized clinical trial. Multiple outcomes of raloxifene evaluation (MORE) investigators. J Am Med Assoc 1999;282:63745 [Erratum in: J Am Mad Assoc 282:2124].

[13] Delmas PD, Ensrud KE, Adachi JD, Harper KD, Sarkar S, Gennari C, et al. Multiple outcomes of raloxifene evaluation investigators. Effi- cacy of raloxifene on vertebral fracture risk reduction in postmenopausal women with osteoporosis: four-year results from a randomized clinical trial. J Clin Endocrinol Metab 2002;87:3609-17.

[14] Rossouw JE, Anderson GL, Prentice RL, LaCroix AZ, Kooperberg C, Stefanick ML, et al. Risks and benefits of estrogen plus progestin in healthy postmenopausal women: principal results from the Women's Health Initiative randomized controlled trial. J Am Med Assoc 2002; 288:321-33.

[15] Powledge TM. NIH terminates WHI oestrogen-only study. Lancet 2004;363:870.

[16] Fillet M, Van Heugen JC, Servais AC, De Graeve J, Crommen J. Separation, identification and quantitation of ceramides in human cancer cells by liquid chromatography-electrospray ionisation tandem mass spectrometry. J Chromatogr A 2002;949:225-33.

[17] Gruber R, Czerwenka K, Wolf F, Ho GM, Willheim M, Peterlik M. Expression of the vitamin D receptor, of estrogen and thyroid hormone receptor alpha- and beta-isoforms, and of the androgen receptor in cultures of native mouse bone marrow and of stromal/osteoblastic cells. Bone 1999;24:465-73.

[18] Bonizzi G, Piette J, Schoonbroodt S, Merville MP, Bours V. Role of the protein kinase $\mathrm{C} 1 / \mathrm{i}$ isoform in nuclear factor- $\mathrm{kB}$ activation by interleukin- $1 \mathrm{~b}$ and tumor necrosis factor-a: cell type specificities. Biochem Pharmacol 1999;57:713-20.

[19] Vermes I, Haanen C, Steffens-Nakken H, Reutelingsperger C. A novel assay for apoptosis. Flow cytometric detection of phosphatidylserine expression on early apoptotic cells using fluorescein labelled Annexin V. J Immunol Meth 1995;184:39-51.

[20] Baffet G, Braciak TA, Fletcher RG, Gauldie J, Fey GH, Northemann W. Autocrine activity of interleukin 6 secreted by hepatocarcinoma cell lines. Mol Biol Med 1991;8:141-56.

[21] Feger F, Ferry-Dumazet H, Mamani Matsuda M, Bordenave J, Dupouy $\mathrm{M}$, Nussler AK, et al. Role of iron in tumor cell protection from the pro-apoptotic effect of nitric oxide. Cancer Res 2001;61:5289-94.

[22] Verheij M, Bose R, Lin XH, Yao B, Jarvis WD, Grant S, et al. Requirement for ceramide-initiated SAPK/JNK signalling in stressinduced apoptosis. Nature 1996;380:75-9.

[23] Sawai H, Okazaki T, Yamamoto H, Okano H, Takeda Y, Tashima M, et al. Requirement of AP-1 for ceramide-induced apoptosis in human leukemia HL-60 cells. J Biol Chem 1995;270:27326-31.

[24] Viereck V, Grundker C, Blaschke S, Niederkleine B, Siggelkow H, Frosch $\mathrm{KH}$, et al. Raloxifene concurrently stimulates osteoprotegerin and inhibits interleukin- 6 production by human trabecular osteoblasts. J Clin Endocrinol Metab 2003;88:4206-13.

[25] Taranta A, Brama M, Teti A, De luca V, Scandurra R, Spera G, et al. The selective estrogen receptor modulator raloxifene regulates osteoclast and osteoblast activity in vitro. Bone 2002;30:368-76.

[26] Hannun YA. Functions of ceramide in coordinating cellular responses to stress. Science 1996;274:1855-9.

[27] Kolesnick R, Golde DW. The sphingomyelin pathway in tumor necrosis factor and interleukin-1 signaling. Cell 1994;77:325-8.

[28] Mathias S, Pena LA, Kolesnick RN. Signal transduction of stress via ceramide. Biochem J 1998;335:465-80.

[29] Fillet M, Bentires-Alj M, Deregowski V, Greimers R, Gielen J, Piette J, et al. Mechanisms involved in exogenous C2- and C6-ceramideinduced cancer cell toxicity. Biochem Pharmacol 2003;65:1633-42.

[30] Huwiler A, Pfeilschifter J, van den Bosch H. Nitric oxide donors induce stress signaling via ceramide formation in rat renal mesangial cells. J Biol Chem 1999;274:7190-5.

[31] Takeda Y, Tashima M, Takahashi A, Uchiyama T, Okazaki T. Ceramide generation in nitric oxide-induced apoptosis. Activation of magnesium-dependent neutral sphingomyelinase via caspase-3. J Biol Chem 1999;274:10654-60.

[32] Marchesini N, Osta W, Bielawski J, Luberto C, Obeid LM, Hannun YA. Role for mammalian neutral sphingomyelinase 2 in confluenceinduced growth arrest of MCF7 cells. J Biol Chem 2004;279: 25101-11. 
[33] Kroesen BJ, Jacobs S, Pettus BJ, Sietsma H, Kok JW, Hannun YA, et al. BcR-induced apoptosis involves differential regulation of $\mathrm{C} 16$ and C24-ceramide formation and sphingolipid-dependent activation of the proteasome. J Biol Chem 2003;278:14723-31.

[34] Reiss U, Oskouian B, Zhou J, Gupta V, Sooriyakumaran P, Kelly S, et al. Sphingosine-phosphate lyase enhances stress-induced ceramide generation and apoptosis. J Biol Chem 2004;279:1281-90.

[35] NIH Consensus Development Panel on Osteoporosis Prevention, Diagnosis, and Therapy. Osteoporosis prevention, diagnosis, and therapy. J Am Med Assoc 2001;285:785-95.

[36] Cheung J, Mak YT, Papaioannou S, Evans BA, Fogelman I, Hampson G. Interleukin-6 (IL-6), IL-1, receptor activator of nuclear factor kappaB ligand (RANKL) and osteoprotegerin production by human osteoblastic cells: comparison of the effects of 17-beta oestradiol and raloxifene. J Endocrinol 2003;177:423-33.

[37] Yang NN, Bryant HU, Hardikar S, Sato M, Galvin RJ, Glasebrook AL, et al. Estrogen and raloxifene stimulate transforming growth factorbeta 3 gene expression in rat bone: a potential mechanism for estrogenor raloxifene-mediated bone maintenance. Endocrinology 1996;137: 2075-84.

[38] Stein B, Yang MX. Repression of the interleukin-6 promoter by estrogen receptor is mediated by NF-kappa B and C/EBP beta. Mol Cell Biol 1995;15:4971-9.

[39] Santana P, Pena LA, Haimovitz-Friedman A, Martin S, Green D, McLoughlin M, et al. Acid sphingomyelinase-deficient human lymphoblasts and mice are defective in radiation-induced apoptosis. Cell 1996;86:189-99.
[40] Franzen R, Pfeilschifter J, Huwiler A. Nitric oxide induces neutral ceramidase degradation by the ubiquitin/proteasome complex in renal mesangial cell cultures. FEBS Lett 2002;532:441-4.

[41] Simoncini T, Genazzani AR. Non-genomic actions of sex steroid hormones. Eur J Endocrinol 2003;148:281-92 [review].

[42] Clarke R, van den Berg HW, Murphy RF. Reduction of the membrane fluidity of human breast cancer cells by tamoxifen and 17beta-estradiol. J Natl Cancer Inst 1990;82:1702-5.

[43] Riggs BL, Hartmann LC. Selective estrogen-receptor modulators: mechanisms of action and application to clinical practice. N Engl J Med 2003;348:618-29 [Review. Erratum in: N Engl J Med 348: 1192].

[44] Dutertre M, Smith CL. Molecular mechanisms of selective estrogen receptor modulator (SERM) action. J Pharmacol Exp Ther 2000;295: 431-7.

[45] Shang Y, Brown M. Molecular determinants for the tissue specificity of SERMs. Science 2002;295:2465-8.

[46] Levenson AS, Jordan VC. Selective oestrogen receptor modulation: molecular pharmacology for the millennium. Eur J Cancer 1999;35: 1974-85.

[47] Yang NN, Venugopalan M, Hardikar S, Glasebrook A. Identification of an estrogen response element activated by metabolites of 17 betaestradiol and raloxifene. Science 1996;273:1222-5.

[48] Kian Tee M, Rogatsky I, Tzagarakis-Foster C, Cvoro A, An J, Christy $\mathrm{RJ}$, et al. Estradiol and selective estrogen receptor modulators differentially regulate target genes with estrogen receptors alpha and beta. Mol Biol Cell 2004;15:1262-72. 